\title{
La dedicatoria a Mars Campester del centurión T. Aurelius Decimus y el campus de la guarnición imperial de Tarraco en el siglo II d.C. Algunas reflexiones sobre la topografía militar de la capital provincial.
}

\author{
Joaquín RUIZ DE ARBULO \\ Universitat Rovira i Virgili \\ Institut Català d'Arqueologia Clássica
}

\section{Resumen}

A partir de distintos epígrafes tarraconenses se reconoce la presencia en los suburbios de Tarraco en el siglo II d.C. de un cuartel para una unidad ecuestre de equites singulares y un campus de ejercicios anexa al mismo. También de unos castra para residencia de dos cohortes. Se considera también el número de los officiales adscritos al gobernador de la provincia que en su caso residían de diferentes formas en el interior del espacio urbano.

\section{Resumé}

À partir des distinctes épigraphes de Tarraco on reconnaît la présence dans les faubourgs de Tarraco au llème siècle d.C. d'un fort pour une unité équestre d'equites singulares et un campus d'exercices annexe au même. Aussi d'uns castra pour résidence de deux cohortes. Il se considère aussi le numéro des officiales assignés au gouverneur de la province qu'ils résidaient de différentes formes au milieu de l'espace urbain.

Palabras clave / Des mots clefs: Tarraco, equites singulares, campus, ora maritima, cohors I et II, cohors nova tironum, officiales, stratores, praetorium consularis.

El 1 de marzo del año 182 a.C., día de la festividad del dios Marte, Titus Aurelius Decimus, centurión de la legión VII con grado de instructor, dedicó en el suburbio de Tarraco un altar a la divinidad por la salud del emperador Cómodo y los equites singulares. Se trata de una inscripción conocida desde el siglo XVI, mencionada en todos los repertorios epigráficos e incluida evidentemente en las RIT de G. Alföldy (CIL II, 4083=ILS 2416= RIT 38) acompañada de un pre-

1 Redactamos con sincero aprecio este pequeño trabajo tarraconense para unirnos al homenaje que los compañeros de la UAM organizan a Manolo Bendala, quien felizmente ha decidido unirse al colectivo de los emeriti en un momento de especial lucidez, conservando íntegras su curiosidad, su capacidad de trabajo, su perspicacia y su sonrisa. Esperamos pues que nos siga regalando trabajos y ensayos ahora escritos por fin desde la calma y sin nocturnidad obligada. Pero ciso comentario que ha sido de nuevo revisado y ampliado recientemente en CIL II ${ }^{2} / 14,839$. Quisieramos ahora comentar de nuevo esta inscripción cuya dedicatoria nos permite asegurar la existencia de un campus, un terreno de ejercicios de la guarnición militar instalada en Tarraco y al hilo de su presencia reflexionar sobre la ubicación de las distintas unidades militares presentes en la capital provincial ${ }^{1}$.

al mismo tiempo no podemos seguir escribiendo sin lamentar profundamente la marcha repentina del maestro Géza Alföldy al que ya no podremos enviar estas líneas como antes hacíamos, para que él nos las devolviera casi en el acto llenas de tachaduras señalando errores y latines mal empleados, con sugerencias y cambios... como hacía siempre y con todos. 
Se trata de un bloque regular labrado en caliza local de Sta. Tecla, con unas medidas de 50 x 45 $\mathrm{cm}$, actualmente encajado en una de las paredes del Palacio Arzobispal Tarraconense (Fig. 1). No podemos saber en su estado actual si se trató de un postamento estatuario o quizás mejor, por su dedicatoria, la parte central de un ara votiva. Formó ya parte de la colección renacentista reunida por Antonio Agustín y debe proceder de un hallazgo realizado en el siglo XVI en las cercanías de la ciudad, en el camino que comunicaba la ciudad renacentista con la vecina Reus, cerca del río Francolí, en el entorno de la actual Pl. Imperial Tarraco. Reproducimos su transcripción añadiendo la traducción castellana:

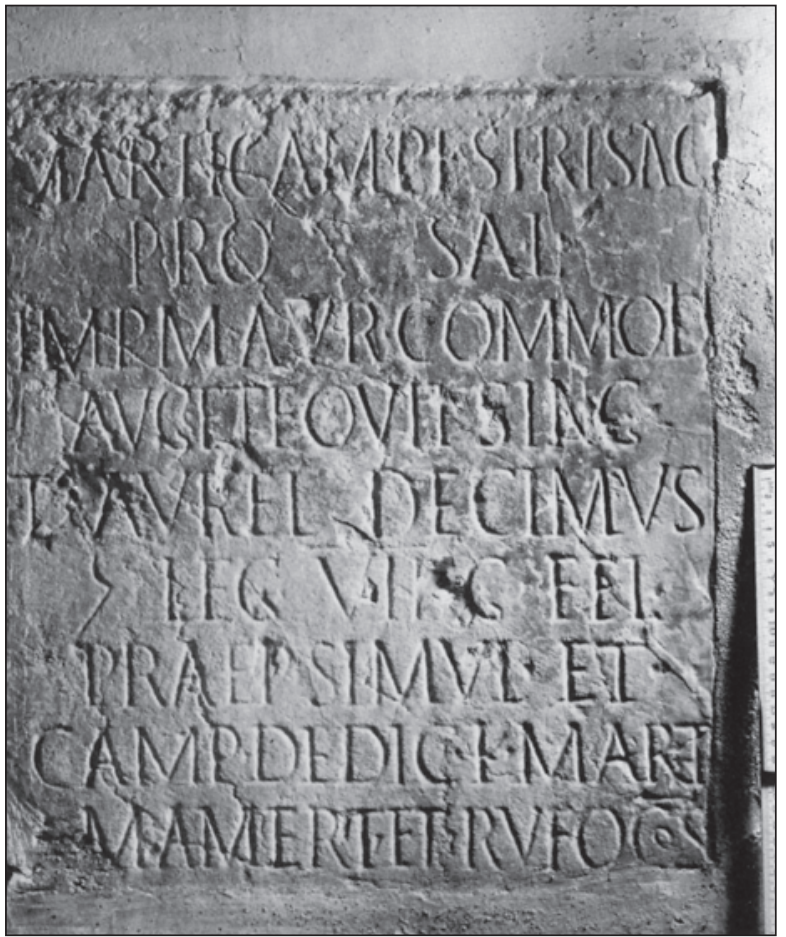

Figura 1. Pieza central del ara dedicada al Marte "del campus" por parte del centurión T. Aurelius Decimus el día 1 de marzo del 182 d.C.

(RIT $\left.38=\mathrm{CIL} \mathrm{II}^{2} / 14,839\right)$

Marti campestri sac(rum) / pro sal(ute) / Imp(eratoris) M(arci) Aure(li) Commodi / Aug(usti) et equit(um) sing(ularium) / T(itus) Aurel(ius) Decimus / (centurio) leg(ionis) VII g(eminae) fel(icis) / praepositus simul et / camp(idoctor) dedic(avit) K(alendis) Mart(iis) / Mamertino et Rufo co(n)s(ulibus)

"Al sagrado Marte del campus, por la salud del emperador Marco Aurelio Cómodo Augusto y los equites singulares. Tito Aurelio Décimo, centurión de la legión VII Gémina, Feliz, a la vez prepósito e instructor, dedicó (esta lápida) en las kalendas de marzo del año de los cónsules Mamertino y Rufo" (1 de marzo del año 182 d.C.).

Se trata de un epígrafe bien conocido en los estudios dedicados al ejército romano (Speidel, 1978: 71-72; Le Roux 1982: 269 y 297; 1998; Southern, 2007; Le Bohec, 2008: 160; Palao, 2006; Alföldy 2007:508). Aunque los epigrafistas siempre han conocido las implicaciones de esta dedicatoria creemos que hasta ahora no se ha señalado de forma suficiente su importancia para reconocer la presencia en Tarraco de un campus, entendido ya no como el espacio urbano dedicado a la formación y esparcimiento de la juventud característico de las ciudades altoimperiales sino explícitamente como el terreno de ejercicios y parada de un acuartelamiento militar.

Efectivamente, el apelativo Marti campestri del epígrafe tarraconense aplicado al dios de Roma y de la guerra, encuentra paralelos con otros altares votivos dedicados sobre todo en Britannia a las divinidades campestres es decir protectoras de las actividades en el campus, el terreno de ejercicios anexo a todo campamento de tropas de caballería, dedicado al entrenamiento de los jinetes y las paradas ecuestres. Unos altares que precisamente eran dedicados en los mismos campi.

Es preciso recordar en primer lugar la diferencia ya señalada por Y. Le Bohec (2008: 159) y diferenciar las dedicatorias a divinidades campestres entendidas como númenes de la naturaleza al modo de las Matres, de aquellas otras divinidades específicas consideradas protectoras de los campusde entrenamiento. Anne Johnson (1983: 217218) recopilaría las dedicatorias y ofrendas conocidas dedicadas a las divinidades "campestres" (Dis campestres o Fatis campestres) en Britannia y el Rhin por parte de alae ecuestres recordando que ya A. von Domaszewski (1895) había señalado su directa relación con unidades de caballería. Los variados ejemplos pueden hoy ser consultados cómodamente en la red gracias a las bases de datos epigráficas de Clauss/Slaby o Heidelberg. El altar aparecido en Auchendavy cerca de Glasgow (Escocia) que el centurión M. Cocceius Firmus de la legió II Augusta dedicara al Marte y la Minerva del campus junto con Hércules, Epona y la Victoria (CIL VII, 01114: Marti / Minervae / Campestri/bus Herc(u)l(i) / Eponae / Victoriae / M(arcus) Coccei(us) / Firmus / I(centurio) leg(ionis) II Aug(ustae)) es un buen ejem- 
plo de cuales fueron divinidades invocadas en estos lugares. Lógicamente encontramos también numerosas salutaciones a Júpiter Óptimo Máximo y a los genios de las distintas unidades. En Maryport, Cumbria, el campus vecino al acuartelamiento de la cohors I Hispanorum equitata contenía hasta 14 dedicatorias a Júpiter Óptimo Máximo por parte de los sucesivos prefectos de la unidad (CIL VII, 823 y ss) y dos al específico Marte de los soldados (Mars militaris) en este caso ofrendadaspor la cohors I Baetasiorum civium Romanorum (CIL VII, 390 y 391). La excavaciones en este acuartelamiento permitieron documentar el desplazamiento de un primer campus donde aparecieron los altares votivos al norte del campamento hacia un nuevo terreno de ejercicios situado al sur donde apareció incluso el podio utilizado como tribunal del terreno de parada (Jarret 1976, cit. Johnson 1983: 217, n.12).

En la propia Roma conocemos, entre otras, dos precisas dedicatorias que nos muestran la variedad de divinidades honradas en el campus, todas ellas protectoras por igual de las milicias ecuestres: Júpiter, Juno, Minerva, Marte, Victoria, Hércules, Mercurio, Felicidad, Salud, Silvano, Apolo, Diana, Epona, junto a númenes específicos como las Fatae o Parcas del campus, las célticas Madres Sulevias o el propio Genio de la unidad. La primera fue dedicada por M. Ulpius Festus, primer decurión de los equites singulares Augusti, la guardia montada del emperador (CIL VI, 31174: I(ovi) O(ptimo) M(aximo) Iunoni Minervae / Marti Victoriae Herculi / Mercurio Felicitati / Saluti Fatis Campestribus / Silvano Apollini Deanae / Eponae Matribus Suleis / et Genio sing(ularium) Aug(usti) / M(arcus) Ulpius Festuss dec(urio) prin(ceps) / eq(uitum) sing(ularium) Aug(usti) / v(otum) s(olvit) l(ibens) m(erito). La segunda es un caso muy similar al tarraconense ya que se trata también de un centurión de la legión VII, P. Aelius Lucius, que al dedicar su voto -entre otras muchas divinidades- al Genius de la unidad de los equites singulares se nos rebela como un antiguo miembro de la misma (CIL VI, 31175: I(ovi) O(ptimo) M(aximo) / Iunoni Minervae / Marti Victoriae Herculi / Fortunae Mercurio / Felicitati Salutis Fatis / Campestribus Silvano / Apollini Dianae Eponae / Matribus Sulevis ceterisque / dis immortalibus / Genio numeri eq(uitum) sing(ularium) Aug(usti) / P(ublius) Aelius Lucius (centurio) leg(ionis) VII Geminae / v(otum) s(olvit) l(ibens) l(aetus) m(erito)).
En resumen, un campus de uso militar sería simplemente una explanada abierta siempre vecina al campamento al que daba uso. Se destinaba a los cotidianos ejercicios de adiestramiento para hombres y caballos especialmente obligados y rutinarios en las unidades de caballería. Un podio o tribunal situado en la cabecera del terreno permitiría a los oficiales la observación de las maniobras. Al mismo tiempo, el campus de entrenamiento se convertiría también en lugar de desfile y parada donde poder celebrar las distintas festividades anuales de la comunidad militar celebrando ejercicios como la famosa hippica gymnasia bellamente descrita por Arriano con grupos de jinetes y caballos ataviados con ricas corazas y bellísimos cascos de cara cubierta portando estandartes con dragones dacios de colas muticolores que se enfrentaban entre sí con lanzamiento de jabalinas. Gracias a las magníficas ilustraciones de Peter Connolly (1989: 46, 54. Ver aquí Fig. 2) podemos hacernos una idea precisa de cómo se realizaban este tipo de ejercicios. En los últimos años, la actividad de los grupos de reconstrucción histórica nos han permitido ver recreados en Tarragona estos ejercicios durante las jornadas Tarraco Viva gracias al trabajo incansable e ímpetu organizador de Magí Seritjol y su grupo de trabajo "Proyecto Phoenix" (www.tarracoviva.com).

Los militares, sus familias y las poblaciones de las cannabae anexas a los campamentos se reunían en estos campi con motivo de las periódicas celebraciones del calendario militar. El espacio común fue por ello sacralizado con la aparición de pequeños espacios sacros anexos. Se trataría siempre de pequeñas capillas o aediculae albergando imágenes de las distintas divinidades y ante las mismas se irían amontonando las aras, arulae $\mathrm{y}$ ofrendas votivas. Ya hemos visto que la lista de las divinidades campestres estaba encabezada por IOM seguido por Marte y Minerva, Hercules, Epona, la Victoria, Mercurio, Apolo y Diana... y en general por todos aquellos númenes queridos por los soldados de cada unidad.

La presencia de este campus de ejercicios hípicos en Tarraco queda doblemente probada por la categoría del dedicante, un antiguo miembro de la guardia montada imperial de Roma, los famosos equites singulares (Augusti), a los que se dedica el altar juntamente con el emperador reinante. M.A. Speidel $(1965 ; 1978 ; 1994)$ ha dedicado diversos trabajos monográficos a esta muy selecta unidad de caballería surgida junto a la 


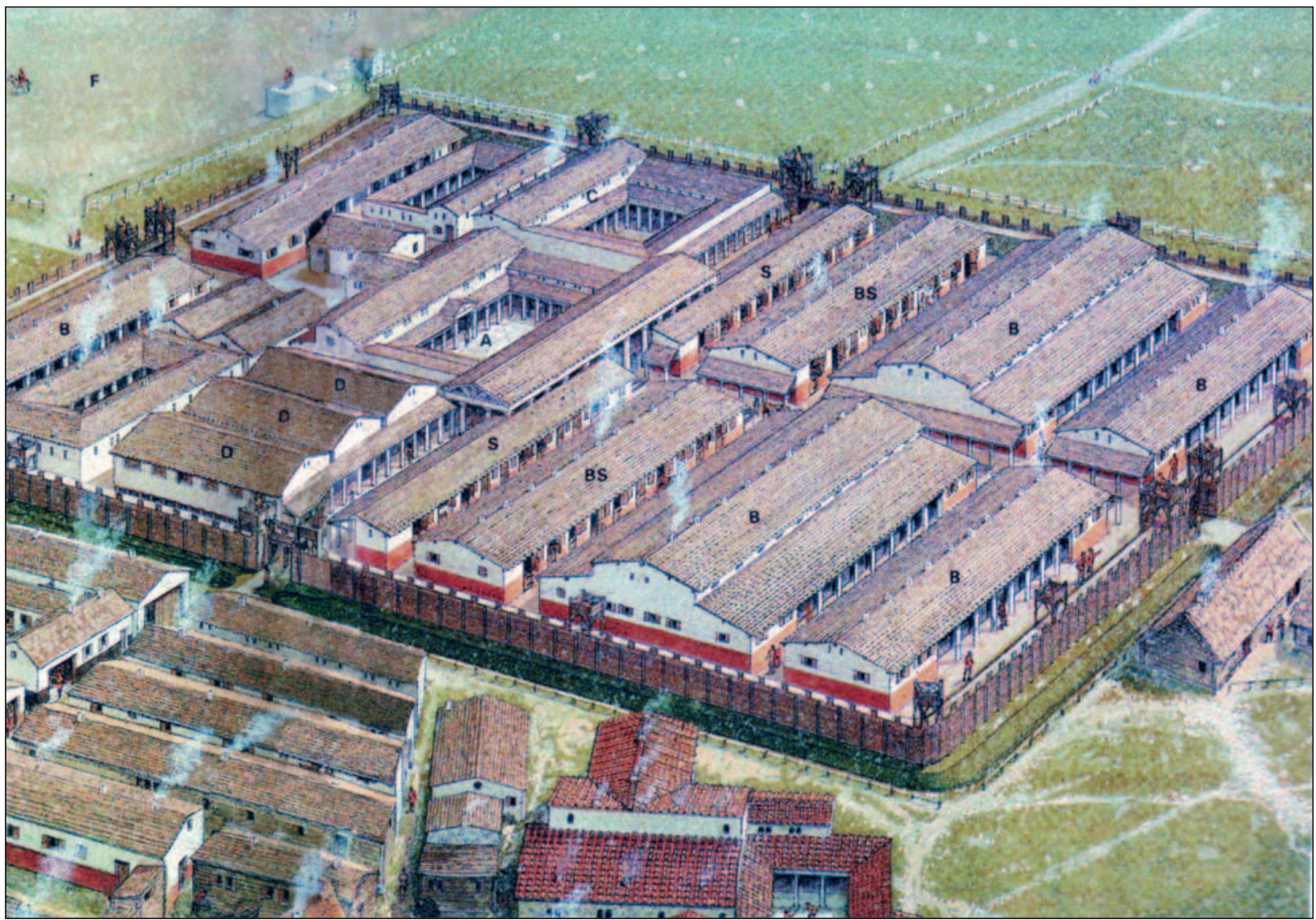

Figura 2. Reconstrucción de P. Connolly (1989) de un pequeño cuartel de caballería como los que conocemos instalados en los limes con una pequeña aglomeración urbana anexa a modo de cannabae. En el ángulo superior izquierdo se incluye el campus de ejercicios incluyendo la plataforma del tribunal y a su lado una aedicula.

guardia pretoriana con la doble finalidad de acompañar al emperador en sus desplazamientos como guardia a caballo y al mismo tiempo poder lucir sus vistosas armaduras y su especial habilidad ecuestre en paradas, desfiles y ejercicios en las fechas señaladas. Eran hombres especialmente seleccionados entre los mejores de las tropas regulares de la caballería auxiliar sometidos a un duro entrenamiento específico y a un sólido espíritu de cuerpo. Su número estimado en Roma a fines del siglo II d.C. sería de unos 2000 hombres equivalentes a cuatro cohortes quingenarias de 500 hombres cada una.

Tras su paso por la guardia montada imperial, Aurelio Décimo fue más tarde centurión de la legión VII. Hemos de considerar que su desplazamiento hasta la capital provincial desde su cuartel en Legio se produjo precisamente por su condición de instructor de jinetes y ejercicios ecuestres (campidoctor). Tuvo pues como encargo entrenar una unidad de caballería para la cual él mismo actuaba como prepósito (praepositus), es decir como responsable y primer oficial. Se trata de un tipo de cargo bien documentado en la epigrafía militar romana aplicado a tribunos, prefectos o centuriones que designaba un mandato asignado con carácter temporal como por ejemplo el mando de una vexillatio. En este caso se trataría evidentemente de la propia unidad montada que él mismo estaba formando.

Hemos de aclarar aquí que nuestra propuesta de traducción del texto de la lápida difiere ligeramente de la de Y. le Bohec (2008: 160) que creyó más conveniente considerar que los equites singulares por cuya salud el centurión Aurelius Decimus ofreció el ara a Marte eran los propios hombres de la unidad tarraconenses. Ciertamente, sin duda estos soldados pudieron ser también equites singulares, pero entendemos que tuvo que ser necesariamente el paso por la selecta unidad de Roma la que justificara la carrera de nuestro centurión como experto jinete antes de pasar a la Legio VII y que en razón de esa experiencia previa fue llamado a Tarraco. Por ello, entendemos mejor que se trate de una dedicatoria genérica a los equites singulares ya fuera el cuerpo primige- 
nio destacado en Roma, los destacamentos presentes en las provincias y la propia unidad en formación. Ello encajaría plenamente con el "sprit de corps" propio de este tipo de unidades de élite. Honrando a la unidad originaria nuestro centurión recordaba a su nueva unidad de soldados promocionados cual era el ejemplo que debían seguir.

Y es que Aurelio Décimo no estuvo solo en su cometido. Pocos años más tarde, a fines del siglo II o inicios del III, murió en Tarraco M. Aurelius Lucilius Poetovioni (Fig. 3) un viejo centurión y también antiguo eques singularis de la guardia imperial con 60 años de edad y cuarenta de servicio en 6 legiones diferentes, siendo la última de ellas la VII Gemina (RIT 178: M(arco) Aur(elio) M(arci) f(ilio) Pap(iria) Lucilio Poetovion(e) / ex singularib(us) Imp(eratoris) I(centurioni) leg(ionis) I / Adiut(ricis) leg(ionis) II Tr(aianae) leg(ionis) VIII Aug(ustae) / leg(ionis) XIIII

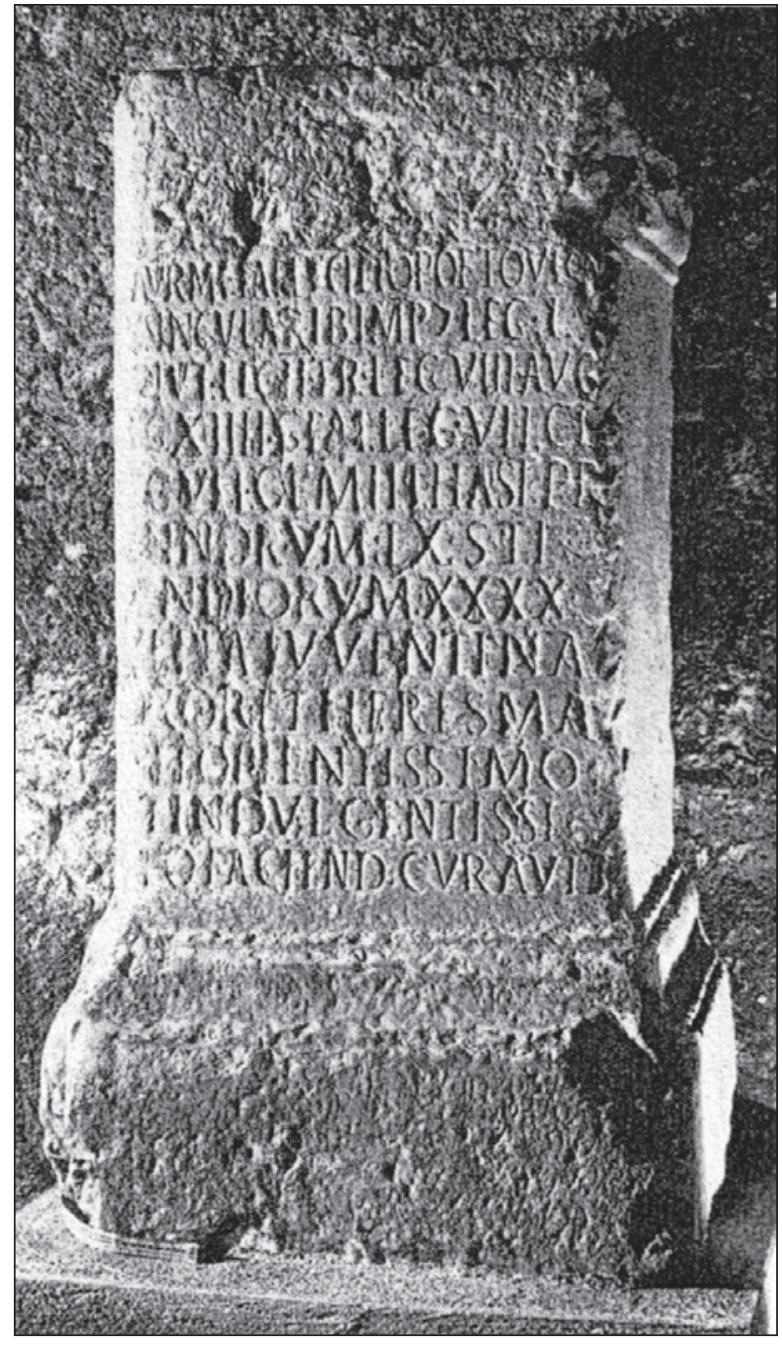

Figura 3. Pedestalfunerario del centurión M. Aurelius Lucilius Poetovioni (RIT 178).
Gem(inae) leg(ionis) VII Cl(audiae) / leg(ionis) VII Gem(inae) III hast(ato) pr(iori) / annorum LX sti/pendiorum XXXX / Ulpia Iuventina / uxor et heres malrito pientissimo / et indulgentissi/mo faciend(um) curavit). Su presencia en Tarraco, junto a su mujer que le dedicó su lapida funeraria y con una edad tan avanzada tuvo que ser de nuevo la de un viejo y experto instructor de jinetes apodado "el de Poetovio", nombre del acuartelamiento de la legio XIIII Gemina en Panonia (la actual Pettau). La expresión ex singularibus Imperatoris utilizada en el epígrafe define en este caso de forma precisa el paso por la guardia montada imperial antes de la promoción a centurión, y esta misma situación, que hemos visto antes también para el centurión Aelio Lucio en Roma, es la que consideramos para el cursus del centurión Aurelio Décimo.

Es probable que este par de muy expertos centuriones instructores de caballería presentes en la Tarraco de fines del siglo II contribuyeran a la formación del soldado de la legión VII Staberius Felix (Fig. 4) que sabemos fue enterrado en Tarraco en fechas algo más tardías (CIL II²/14, 1062: D(is) M(anibus) s(acrum) / Staberio Felic[i] / mil(iti) leg(ionis) VII gem(inae) p(iae)

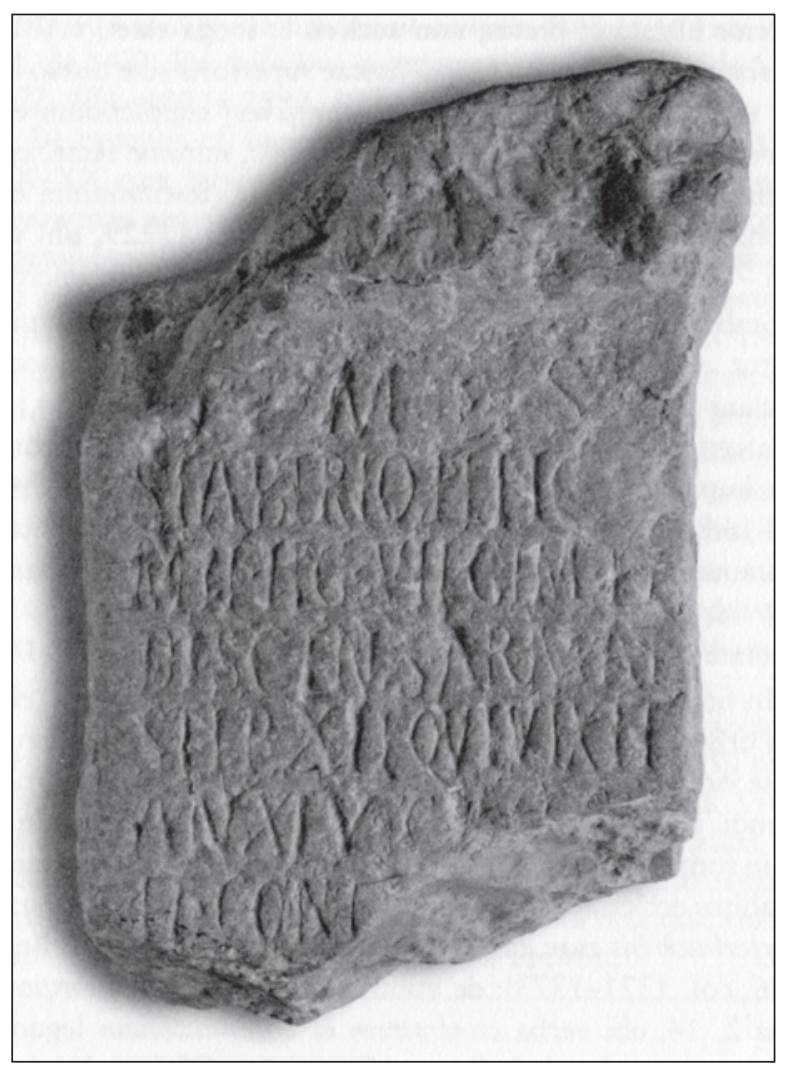

Figura 4. Pedestal funerario del soldado Staberius Felix, discens armaturae (CIL II $2 / 14,1062)$. 
f(elicis) / discens armat(urae) / stip(endiorum) XII qui vixit / an(nis) XLV cives / et conf[ratres] /-). G. Alföldy (1991) dedicaría un trabajo específico a su epitafio ya que el desarrollo de la línea 4 permitía tanto pensar en un cargo de dis(pensator) cen(sus) Sarmat(ici) como de un grado militar como discens armaturae por el que finalmente se optó. Ciertamente, la adscripción del militar a la legión VII difícilmente podía cuadrar con un cargo en las muy lejanas tierras de los sármatas. El vocablo discens tuvo claramente en la epigrafía militar romana un concepto de aprendizaje y formación que encontramos ligados a distintos grados o especialidades: discens aquiliferum, discens signiferum, discens equitum, discens armorum, discentes capsariorum... ("Aquel que aprende un arte, escolar" en QUINTIL. I, 3 y SUET, gramm. 7. s.v. Discens, Diz. Epi. II, 3: 19101911). Su relación con el equipamiento militar de las armaturae pudo quizás hacer relación con la custodia del armamento (discens armorum en CIL XIII, 6824) y los equipos como custodes armorum, uno de los cargos legionarios reservados a los legionarios ya immunes (Palao, 2006:137). Pero también pudo tratarse, como ha considerado mejor P. Le Roux (1998: 92), de un estadio de formación para pasar de la infantería a la caballería en la línea de los discentes equitum documentados en CIL V 8278 y CIL VIII, 2882). Ello cuadraría perfectamente con la unidad formada por Aurelio Décimo. Por su nombre, Staberius fue en cualquier caso un personaje de origen africano que fue enterrado cerca de la villa de Mas dels Canonges donde viviría ya como veterano retirado del servicio.

El doble carácter del centurión Aurelio Décimo como praepositus simul et camp(idoctor) nos permite pues asegurar la presencia en Tarraco de una unidad de caballería, probablemente una simple centuria. Speidel (1978) ha señalado como la epigrafía se refiere también a la presencia de tropas singulares tanto infantes como jinetes situadas en las provincias conservando su cometido de guardia personal de acompañamiento. Hemos pues de considerar que a fines del siglo II d.C., el conjunto de officiales puestos al servicio del gobernador para el tratamiento de todo tipo de temas de administración militar, judiciales y de orden público, se complementó con un destacamento de tropas de parada a caballo para cus- todia específica del gobernador y de su séquito. También lógicamente, hemos de pensar, para lucimiento y exhibición en las grandes ceremonias anuales. En cualquier caso hemos también de tener en cuenta el difícil momento histórico de la dedicatoria y a ello dedicaremos unas líneas al final de este trabajo.

El campus de entrenamiento de esta unidad situado en el área suburbana de Tarraco en dirección al cauce del Francolí y el cruce del río en dirección al suroeste nos obliga a imaginar la presencia anexa al campus de un pequeño campamento, un fuerte para el alojamiento de los hombres con cuadras para los caballos, tal es la evidencia arquitectónica y arqueológica que nos transmite este epígrafe. Ahora bien, si de esta forma completamos la información específica que podemos extraer de este altar votivo ciertamente hemos también que considerar otras variadas menciones de la epigrafía tarraconense en relación a los militares instalados en la ciudad. Poseemos ya dos trabajos específicos dedicados a este tema: una densa conferencia de P. Le Roux (1998) sobre "Ejército y sociedad en Tarraco" y la contribución de G. Alföldy (2007) "El ejército romano en Tarraco" incluida en la miscelánea sobre el ejército romano en Hispania reunida por Angel Morillo. Son dos síntesis breves llenas de sugerencias útiles que han de ser completadas con las múltiples referencias incluidas por Juan José Palao (2006) en su estudio fundamental sobre la Legión VII.

Además de la centuria de equites singulares entrenada por Aurelio Décimo sabemos que en Tarraco estuvieron estacionadas en el siglo II d.C. dos cohortes numeradas I y II bajo el mando de prefectos y en directa relación con la Ora Maritima o distrito naval, además de una tercera cohors nova tironum compuesta según su nombre por reclutas recien alistados (tirones). Como grupo aparte hemos de recordar también la presencia en Tarraco del officium provincial en que estaban destacados de forma permanente los officiales, un contingente de militares de la legión VII empleados en labores de administración, justicia, orden público y comunicaciones al servicio del gobernador y de su actividad judicial y administrativa. Para todos ellos hemos de buscar lugares de residencia específicos (Fig. 5). 


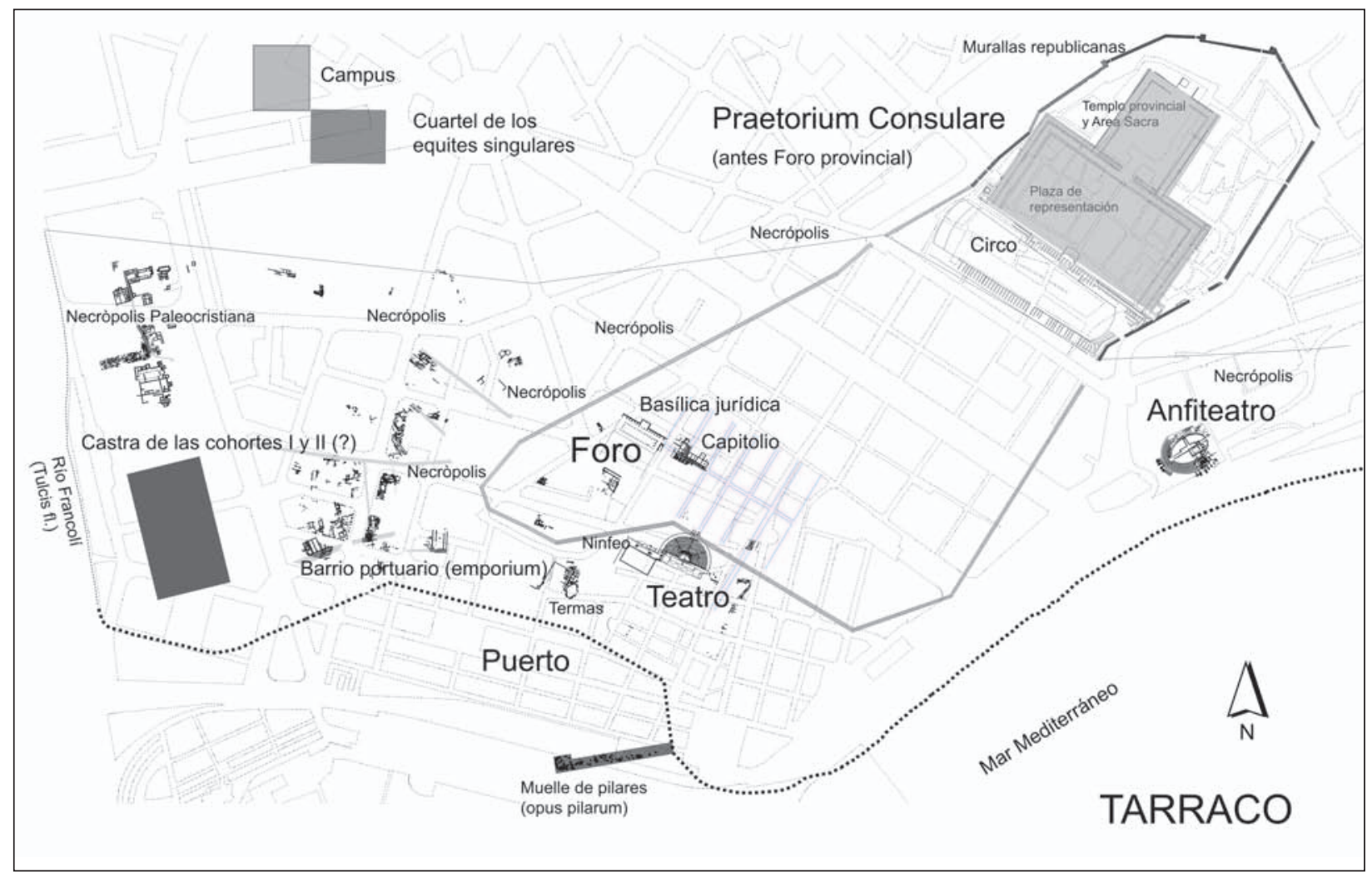

Figura 5. Restitución de los principales elementos de la arquitectura pública de la ciudad de Tarraco a fines del siglo II d.C. con propuesta de ubicación de las principales instalaciones militares. La ubicación del cuartel y campus de la unidad de caballería se basa en el lugar de hallazgo del altar de Aurelio Décimo. La posición de los castra de las cohortes I y II es hipotética, los hemos situado junto al río Francolí, cerca del puerto que debían vigilar, en un sector sin hallazgos arqueológicos significativos (Macías y Fiz dirs. 2007). Pero también pudieron estar situados junto al río, un poco más al norte configurando junto al cuartel de la caballería un barrio suburbano de usos militares.

\section{El PRAEFECTUS ORAE MARITIMAe Y EL MANDO SOBRE LAS COHORTES I, II Y NOVA TIRONUM.}

Con las reformas sociales y militares realizadas por Vespasiano en el ámbito provincial han sido puestas en relación nuevas prefecturas de orden menor relacionadas con el mando de tropas, la vigilancia de las costas y la administración de las islas Baleares que encontramos documentadas de forma exclusiva en Tarracopor su carácter de capital provincial.

Conocemos en el conjunto epigráfico tarraconense diversos tituli honorarios y funerarios escalonados desde Vespasiano a mediados del siglo II d.C. que fueron ofrendados a jóvenes, en su mayor parte originarios de Tarraco que completaron sus carreras de magistrados urbanos con una prefectura ecuestre de carácter menor que figura mencionada como la ora marituma / maritima, en uno de los casos precisada como ora maritimae Laeetanae (RIT 162, 164, 165, 166, 167, 169, $171,288,289,301,316)$. La prefectura de esta
Ora Maritima iba ligada al mando sobre dos cohortes numeradas I y II y de una tercera unidad mencionada como "nueva cohorte de los reclutas". Todos los estudiosos de estos epígrafes concuerdan en que estas cohortes debían estar puestas al servicio del distrito naval con tareas de policía, comunicación o simple vigilancia (Barbieri, 1946; Roldán, 1974: 227-228; Le Roux, 1982: 153-157).

La mención de una ora maritima o distrito naval en las costas tarraconenses estaba ya documentada en el epígrafe funerario de $C$. Baebius en Forum Livii en la época de la batalla de Actium (CIL XI, 623 = ILS 2672 = Roldán 1974, núm. 484: C(aius) Baebius T(iti)f(ilius) Clu(stumina) / tr(ibunus) mi[l(itum) leg(ionis X]X? praef(ectus) / ora[e marit(imae) Hi]span(iae) / citer(ioris) [- b]ello / Actiensi IIIIvir i(ure) d(icundo) / arb(itratu) M(arci) Sappini L(uci) f(ili) et Gallae l(ibertae) -) y de nuevo conocemos maniobras de control de las costas provinciales durante los enfrentamientos del año 69, cuando Galba encar- 
gó al prefecto $Q$. Pomponius Rufus la defensa del litoral hispano ante un posible ataque de la flota del Miseno (Le Roux 1982, 153). No obstante, los estudios epigráficos de G. Barbieri (1941 y 1946) probarían que a fines del siglo I d.C. el cargo de praefectus orae maritimae, documentado en las provincias Tarraconense, Bética, Mauritania y Bitinia era un cargo menor que formaba parte de las primeras milicias ecuestres preparando para el ejercicio de otros mandos y procuratelas de mayores responsabilidades.

Las tareas de esta prefectura debían ser básicamente de policía y vigilancia, controlando los puertos ysus accesos. El Digesto incluye igualmente las pesquisas judiciales en caso de naufragio. En realidad las actuaciones militares navales en las costas hispanas correspondían a las flotas del Miseno y de la muy lejana Ravenna. En Dertosa conocemos como caso particular el epitafio del soldado L. Numisius Liberalis, originario de Córcega, marinero de la trirreme "Marte" integrada en la flota pretoria de Ravenna (classis praetoriae ravennatis), cuya lápida corrió a cargo de su mujer Gellia Excitata y de M. Didius Pollio, uno de sus compañeros (commanupularis) que consta como heredero (CIL II, 4063: D(is) M(anibus) / L(ucius) Numisius Li/beralis mil(es) / cl(assis) pr(aetoriae) Ravenn(atis) / III(triere) Mart(e) stip(endiorum) XIII / nat(ione) Cursican(us) / M(arcus) Didius Pol/io heres et com/manip(ularis) et Gellia / Excitata). Si la mujer de Numisio Liberal residía en Dertosa y también uno de los compañeros de la nave hemos de imaginar que la trirreme Marte estuvo destacada en el puerto de Dertosa al menos durante un tiempo.

Los cursus de los diferentes prefectos de la ora maritima presentan variables importantes y las discusiones eruditas entre los epigrafistas respecto a si sus cargos deben ser leídos en orden directo o indirecto no arrojan demasiada luz sobre el planteamiento global de la cuestión (Le Roux 1982, 155). En el caso del tarraconense L. Cornelius Celsus (RIT 169) su mando sobre el distrito naval y las cohortes I y II (fig. 6) así como el de su conciudadano Licinius Laevinus (RIT 171) sobre el distrito naval y la nueva cohorte de reclutas (fig. 8) fueron simplemente la continuación de sus carreras como magistrados urbanos y no tuvieron cargos pos-

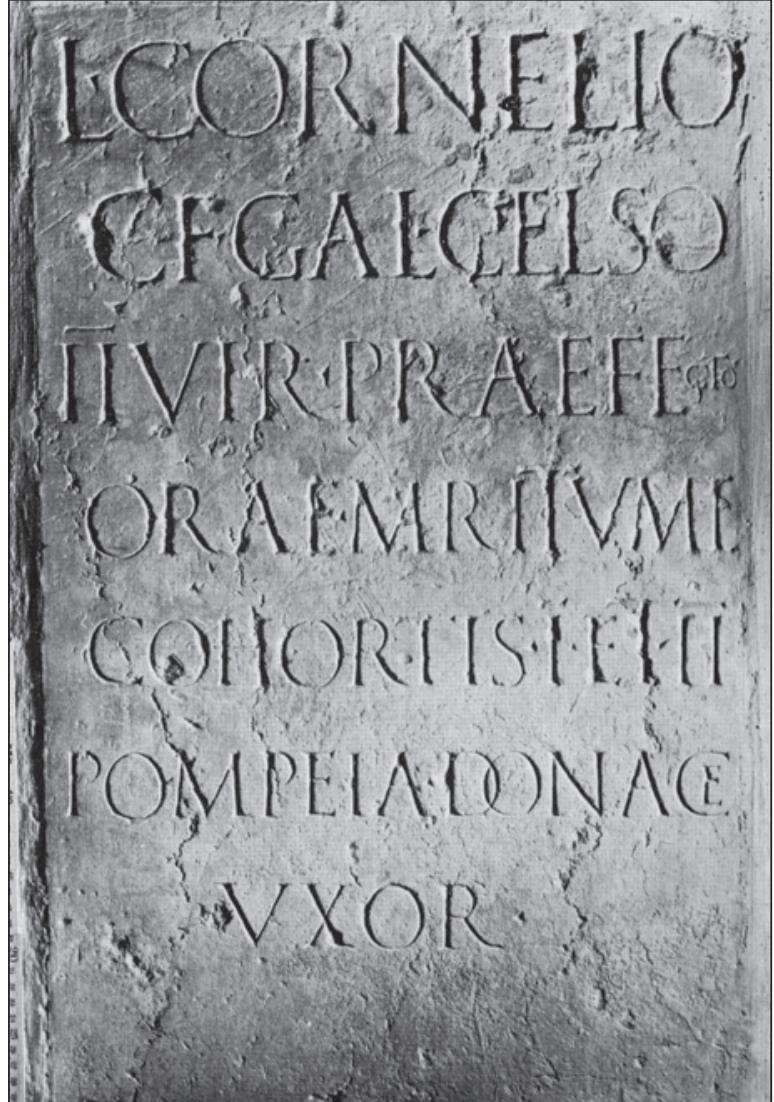

Figura 6. Postamento estatuario ofrendado por Pompeia Donace a su marido L. Cornelius Celsus mostrando su cursus de duumvir, prefecto de la Ora Maritima y de las cohortes I y II. (RIT 169)

teriores, es decir que la prefectura de la ora maritima y las cohortes significó para estos personajes simplemente una promoción de dignidad ecuestre que les permitíamanifestar su ascenso social tras los años de servicio a la ciudad como magistrados. En el caso de $L$. Caecina Severus (RIT 164 y 165) entre las magistraturas urbanas y el mando sobre la ora maritima y la cohorte I se añadiría además la prefectura de los fabri y ello significaba mayores responsabilidades al servicio del gobernador provincial (fig. 7).

Muy diferente fue la carrera militar ecuestre de M. Porcius Narbonensis (RIT 301) que fue tribuno en la legión XXII y prefecto de una ala de caballería antes de responsabilizarse de la ora martimay más tarde ocupar el prestigioso flaminado provincial. También fue más dilatada y compleja la carrera de $Q$. Licinius Silvanus Granianus pues este rico caballero, de familia quizás originaria de Aeso, y cuyo hijo llegaría a ser senador y consul del año 106, recibió dos estatuas en Tarraco recordando que además de 


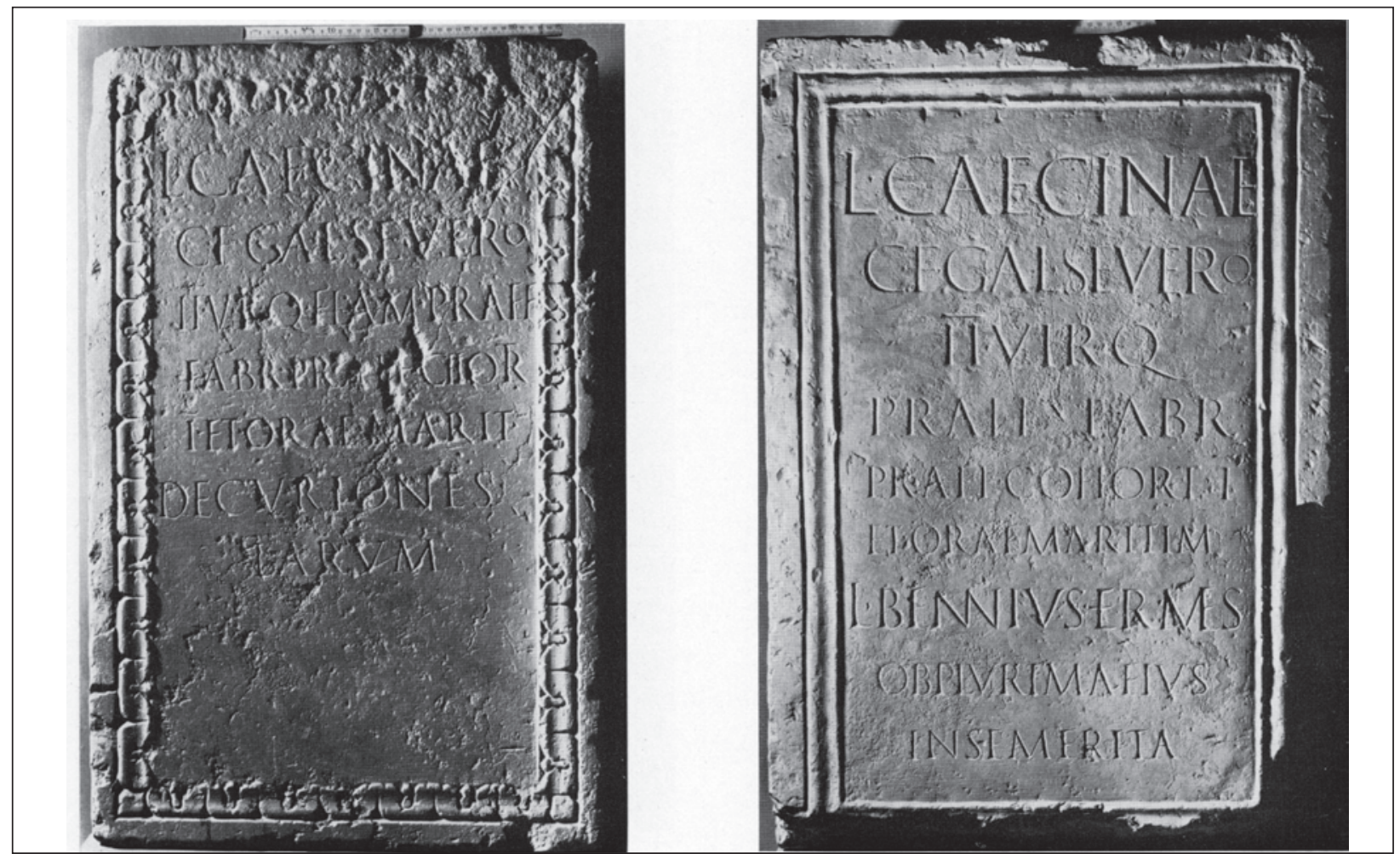

Figura 7. Postamentos estatuarios ofrendados a L. Caecina Severus mostrando un cursus urbano tradicional prolongado con la prefectura de los fabri, el mando de la cohorte I y de la Ora Maritima. (RIT 164 y 165)

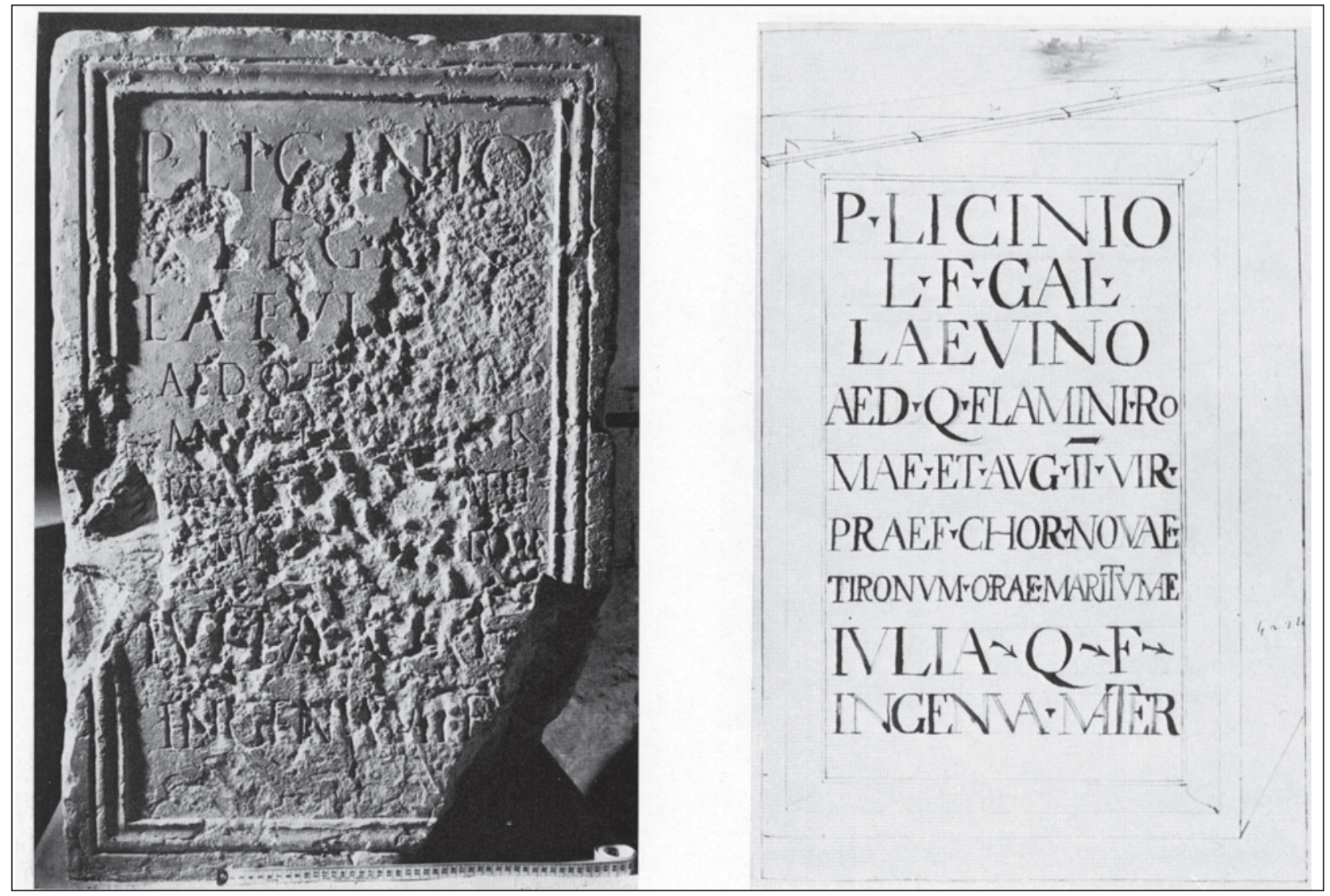

Figura 8. Postamento estatuario ofrendado a P. Licinius Laevinus recordando su paso por las magistraturas urbanas y posteriormente el mando de la "nueva cohorte de los reclutas" antes de acceder a la prefectura de la Ora Maritima. Foto: RIT 171 restitución de Y. Boy a fines del siglo XVIII 
prefecto de la ora maritima llegaría a ser flamen de la provincia y también procurador de la misma. En uno de los epígrafes (RIT 288) Licinius Silvanus fue mencionado simplemente como praefectus orae maritimae mientras que en el segundo (RIT 289) aparece como praefectus orae maritimae Laeetanae. La Laietania citada por Ptolomeo $(2,6,18)$, con viñedos alabados por Marcial $(1,49)$ y Plinio $(14,71)$ correspondía a una de las regiones de la costa provincial tarraconense, al norte del río Llobregat, que sabemos comprendía las ciudades portuarias de Barcino, Baetulo e Iluro. No pudo tratarse de una simple abreviatura ya que lógicamente la ora maritima debía extenderse a toda la costa del conventus tarraconensis desde los Pirineos al río Júcar y no únicamente al sector de la regio Laeetania. Curiosamente, sabemos por la preciosa tabula de patronazgo encontrada en Badalona (IRC 1,139) que los habitantes de Baetulo nombraron patrono de la ciudad a un Licinius Silvanus Granianus que pudo ser este mismo caballero o bien su hijo ya senador, pero no podemos explicar la razón de la distinta denominación de la prefectura en ambos epígrafes. Otro de los personajes, $T$. Claudius Paullinus (RIT 167), fue además de prefecto de la ora maritima también prefecto de las Baleares (praefectus insularum Baliarum) en un momento de probables conflictos ya que la islas dependían normalmente del vecino conventus de Carthago Nova.

Esta prefectura marítima en conclusión debía contar con el apoyo de una o dos unidades militares que los epígrafes mencionan como las cohortes I y II. Cada una de estas cohortes, formada por 6 centurias, tendría unos efectivos de aproximadamente 500 hombres y debían conformar ciertamente una guarnición. Sabemos que L. Cornelius Celsus (RIT 169) fue prefecto de ambas cohortes I y II además de la ora maritima por lo cual entendemos que debía tratarse de dos unidades diferenciadas y coetáneas.

En otros casos la prefectura militar se ejerció sobre una cohorte denominada nova tironum, cuyo mando tuvo por ejemplo el ecuestre $L$. Antonius Silo (RIT 162) que ostentó también la prefectura de los fabri y el mando sobre la cuarta cohorte de los tracios. Pierre Le Roux ha propuesto que se tratara de una nueva cohorte formada como indicaba su nombre por reclutas (tirones) creada quizás en un momento concreto de falta de efectivos y que esta unidad se convertiría luego en la cohorte II. La presencia de una "nueva" cohor- te de reclutas debe ser explicada por la presencia entre las diferentes oficinas del gobierno de la provincia de una oficina de reclutamiento donde los voluntarios para el servicio militar pudieran engancharse y someterse a los meses de entrenamiento previos a su juramento como legionarios (milites). Durante este periodo de marchas, manejo de las armas y aprendizaje de los movimientos de combate bajo el mando de instructores específicos los reclutas eran denominados tirones.

Junto al campus de fines del siglo II destinado a los ejercicios ecuestres de como mínimo una centuria de caballería cuyo acuartelamiento tuvo que estar situado en sus inmediaciones debemos ahora concluir igualmente que tuvieron que existir unos castra para el alojamiento de dos cohortes (con aproximadamente 1000 hombres), destinadas a la protección de la ora maritima. En un momento determinado quizás debido a la falta de efectivos tuvo igualmente que formarse una nueva cohorte con jovenes reclutas en formación. La presencia de estos efectivos precisarían de un asentamiento colectivo exterior, un pequeño campamento estable al modo de los castra praetoria de Roma aunque lógicamente de mucho menor tamaño. Podemos pues pensar en la presencia de una única fortificación campamental o bien mejor considerar que las distintas unidades tuvieron residencias diferenciadas, unos pequeños castra para las tropas de infantería y un fuerte destinado a la unidad de los jinetes singulares. Debemos imaginar la situación de ambos campamentos en los terrenos próximos al río Francolí que facilitaban un rápido aceso al puerto y a la red de vías que circundaban la ciudad además de proporcionar terrenos llanos en el entorno donde poder realizar los ejercicios de adiestramiento tan necesarios para los jinetes singulares como para los jovenes reclutas de la "nueva cohorte". Nuestra propuesta para la situación de ambos campamentos se basa en el lugar del hallazgo del altar de Aurelio Décimo para el fuerte de la caballería y en la lógica de situar los castra de las cohortes en los terrenos vecinos al río por su proximidad al puerto, a la red de comunicaciones y la presencia de zonas llanas vecinas. No podemos descartar sin embargo que ambas unidades compartieran unos mismos castra o que estos estuvieran situados uno junto a otro configurando una área suburbana de usos militares. Pero los trabajos recientes de arqueología urbana no han proporcionado de momento evidencias de asentamientos militares suburbanos (Macías y Fiz eds. 2007) 


\section{EL PRAETORIUM CONSULARIS TARRACO- NENSE.}

En otros trabajos (Ruiz de Arbulo, 1994; 2008) hemos insistido sobre la diferencia que puede establecerse entre las urbanizadas capitales provinciales de Hispania frente a las capitales provinciales "más alejadas" de las Tres Galias, Retia o las dos Germanias a la hora de considerar el diferente papel urbanístico que parecen jugar en unas y otras los praetoria consularis. En Lugdunum, Ara Agripinensium o Mogontiacum, los gobernadores contaban con auténticos palatia organizados como suntuosas villaecon peristilos, espacios públicos y privados, grandes salas de audiencia y dependencias para los officiales destinados al servicio provincial (Desbat, 2004; Haensch, 2004). Por el contrario nada parecido encontramos en Tarraco, Corduba y Emerita Augusta a pesar de que sabemos que las tres ciudades contaban con idénticos equipos de gobierno de rango cónsular.

En el caso de Tarraco podemos añadir a este debate un documento epigráfico explícito y es la dedicatoria que el gobernador Titus Flavius Titianus y su mujer Postumia S[i]ria dedicaron durante su mandato a la tríada capitolina y al genius praetorii consularis (fig. 9) en época de Septimio Severo o de Caracalla, c. 199-209 d.C. (RIT 34: I(ovi) O(ptimo) M(aximo) / Iunoni / Minervae / Genio praetorii / consularis / diis Penatibus / T(itus) Fl(avius) Titianus / leg(atus) Augg(ustorum) pr(o) pr(aetore) / Postumia S[i]ria / eius / dicaverunt). Si entendemos este praetorium consularis como una gran y lujosa domus de tipo palacial no parece posible que se situara en el espacio existente en torno a la estructuras del foro provincial tarraconense. Hasta ahora han sido numerosas las intervenciones arqueológicas realizadas en todo este sector entre las murallas y el gran recinto, siempre sin resultados tangibles (Ruiz de Arbulo 2008). Pero también podemos reflexionar sobre otra coincidencia histórica.

Sabemos que en el conjunto de la epigrafía romana de Tarraco los homenajes dedicados por el concilium provinciae y los recibidos por los gobernadores provinciales todos ellos procedentes de la parte alta de la ciudad en el recinto que denominamos el "Foro provincial" tarraconense (Ruiz de Arbulo, 2008) no son contemporáneos sino que sucesivamente se sucedieron en el tiempo, coincidiendo significativamente con la batalla de Lugdunum. Esta batalla, librada en el año 197 d.C., acabó con el levantamiento de Clodius Albinus aclamado como Augusto en el 195 d.C. por las tropas del Occidente romano frente a la nueva autoridad imperial representada por Septimio Severo, que había iniciado una idéntica aventura en el 194 al marchar contra Roma desde su puesto como gobernador de Pannonia y más tarde enfrentarse a Pescenius Niger al mando de las legiones de Oriente. Entre los partidarios de Albino, además de buena parte del orden senatorial romano se encontraba la flor y nata de la nobleza provincial de la Galia e Hispania, contra todos los cuales Severo emprendería una represión sin precedentes (SHA, Sev. XII; Arce, 1981). El nombre de Novius Rufus, gobernador de la provincia entre el 192 y el 197 aparece en la lista de senadores que Severo haría ejecutar (Alföldy, 1966: 42-43, n. 106).

De forma significativa, la batalla de Lugdunum señala en el foro provincial de Tarraco la aparición de una serie repetida de lápidas con

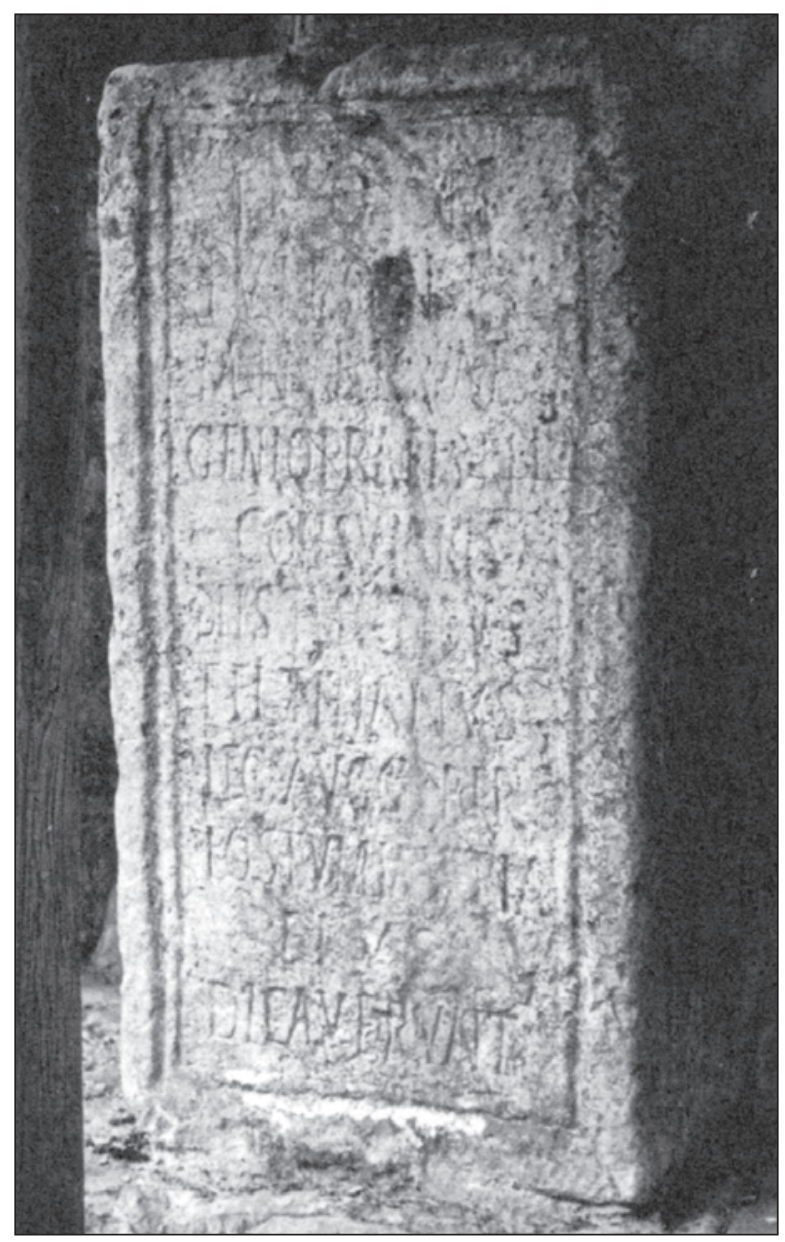

Figura 9. Altar dedicado a la Tríada capitolina y al Genius praetorii consularis por el gobernador Titus Flavius Titianus y su mujer Postumia S[i]ria (RIT 34). 
homenajes a los sucesivos gobernadores por parte de los militares integrados en sus officia. Nunca hasta este momento los gobernadores provinciales habían recibido homenajes estatuarios explícitos en el recinto provincial y ahora sin embargo estos aparecen expresados de forma continuada para cada uno de los nuevos praesides. La desaparición de las dedicatorias de la asamblea provincial y su sustitución por los officiales al servicio de la administración provincial no hace sino evidenciar un proceso de "militarización" bien documentado de la administración imperial que fue potenciado por Septimio Severo hasta límites que anunciaban la entrada en un nuevo periodo histórico.

En 1722 el almirante ingles Stanhope se llevó de Tarragona una lápida con largo texto latino hoy en día expuesta en el Museo Britanico (RIT 130). Se trata de un pedestal dedicado a Ti. Claudius Candidus, uno de los mejores generales de Septimio Severo enviado por éste a Hispania como nuevo legado propretor en el 198, mostrando su amplísimo cursus militar, admisión en el Senado y ascenso hasta el cónsulado, pudiendo luego ejercer un cargo procónsular como era el gobierno de la Hispania citerior. Dedicó la estatua su asistente (strator eius), Silius Hospes, un centurión de la legión X acantonada en Panonia, que probablemente le habría servido como ayudante a lo largo de todas sus campañas. Claudio Candido es ya citado como praeses (optimo praesidi), el nuevo título que a partir de ahora designaría oficialmente a los gobernadores provinciales (RIT 130/CIL II ${ }^{2}$ 14, 975: Tib(erio) Cl(audio) Candido co(n)s(uli) / XVvir(o) s(acris) f(aciundis) leg(ato) Augg(ustorum) / pr(o) pr(aetore) provinc(iae) $H$ (ispaniae) c(iterioris) / et in ea duci terra marique / adversus rebelles hh(ostes) pp(ublicos) / item Asiae item Noricae / duci exercitus Illyrici / expeditione Asiana item Parthica / item Gallica logistae civitatis / splendidissimae Nicomedensium / item Ephesiorum leg(ato) pr(o) pr(aetore) provin(ciae) / Asiae cur(atori) civitatis Teanensium [[AL]] / allecto inter praetorios item / tribunicios proc(uratori) XX hered(itatium) per / Gallias Lugdunensem et Bel/gicam et utramq(ue) Germaniam / praeposito copiarum expediti/onis Germanicae secundae / trib(uno) mil(itum) leg(ionis) II Aug(ustae) praefecto / coh(o)rtis secundae civium / Romanorum / Silius Hospes hastatus leg(ionis) X / Geminae strator eius / optimo praesidi).
Claudio Candido cayó en desgracia y fue sustituido por un nuevo legado, el consular $T$. Claudius Titianus (RIT 135) mencionado como leg(ato) Augg(ustorum) nn(ostrorum) pero también como praesidi prov(inciae) Hisp(aniae) citerioris. Claudio Titiano recibió un pedestal estatuario a cargo de un tal $M$. Aurelius Modestinus, del que no consta el cargo pero que fue probablemente su jefe de gabinete (princeps officii). El texto del epígrafe iba acompañado en los laterales del pedestal por dos largas listas con otros 38 nombres sin especificar cargos. Titianus sería gobernador en los años 199/202 aunque es también posible que lo fuera en el periodo 205 / 208.

Tenemos datos más precisos para el gobierno de Q. Hedius Rufus Lollianus Gentianus (RIT 139 y 140) que gobernó la provincia durante los años 202-205 realizando un nuevo censo de la misma. Se trataba de un administrador experto que ya había realizado el censo de toda la Galia tras la victoria de Albino en los años 198-200, siendo después procónsul de Asia (años 201-202). Estos nuevos censos de la Galia e Hispania convertirían en oficiales los resultados del programa de confiscaciones y subastas de bienes de los prohombres ejecutados o sancionados por Severo. El patrimonio imperial, enriquecido con una buena parte de estos bienes, adquirió un volumen nunca hasta entonces conocido. Una de las dos estatuas que recibió en Tarraco el gobernador y censor Hedius Rufus (RIT 140) le fue dedicada por los militares de su officium: dos cornicularii, dos commentarienses y diez speculatores, procedentes todos ellos de la legión VII Gemina.

Conocemos también el breve epígrafe funerario del gobernador M. Maecius Probus (RIT 142) muerto en la ciudad y recordado por su mujer Pomponia Arria y su hijo, el niño M. Pomponius Maecius Probus que acreditan claramente su condición senatorial como c(larissima) f(emina) y c(larissimus) p(uer). El mandato de Maecio Probo ha de situarse igualmente entre los años 198 y 209.

Probablemente, al igual que ocurriera en las provincias vecinas de la Galia Narbonense, Betica y Africa, el flaminado provincial y con él las ceremonias anuales siguieron existiendo pero al menos en Tarraco sus fastos ya nunca tuvieron el esplendor y el compromiso personal de épocas pasadas. El último flamen provinciae documentado que fue honrado con una estatua por el concilium fue $M$. 
Iulius Serenianus Adoptivus (RIT 284), originario del lejano convento Lucense, al que Cómodo nombraría caballero y cuya lápida tarraconense además de honrarle como flamen le menciona como patrono m[erentissimo], una evidencia de la búsqueda de mayores apoyos por parte de un consejo provincial que decidió igualmente levantar otra estatua a su hijo M. Iulius Adoptivus recordando los dones de su padre. De fechas similares conocemos otra estatua de datación quizás algo posterior dedicada a la flaminica [pHc]? Aurelia Marcellina (RIT 320), originaria del conventus cluniense y mujer del flamen Licinius [Spar]sus, pero los dedicantes fueron ya los cives tarraconenses y no la asamblea provincial.

Si los nuevos praesides fueron homenajeados por sus officiales en el interior del espacio provincial el concepto de praetorium consularis debe ser asignado en Tarraco a la totalidad del conjunto arquitectónico del foro provincial. Una denominación que en realidad simplemente resaltaría las funciones de gobierno, justicia y administración que desde su origen ya habría tenido el gran conjunto público tarraconense, pero que ahora adquiría un protagonismo mucho mayor en una sociedad romana que en los inicios del siglo III estaba asistiendo a un proceso imparable de concentración del poder exclusivamente en torno al emperador y sus hombres de confianza, un proceso que no dejaría de incrementarse en las siguientes décadas.

\section{LOS OFFICIALES DEL PRAETORIUM CONSU- LARIS.}

El legado gobernador tenía siempre a su lado un asistente denominado strator, "el que ensilla un caballo", cuya función primigenia debía ser lógicamente el cuidado de su montura, pero que en realidad actuaba como un ayudante de campo en todos los órdenes. El rango más habitual, como en el caso del hastatus Silius Hospes, strator del legado Claudius Candidus, era el de centurión. Como recordaría un estudio de Sabino Perea (1998) los stratores no conformaban un grado dentro de la jerarquía militar sino una especialidad concreta alejada de la vida cotidiana en los castra que estaba adscrita al servicio de los altos cargos de rango senatorial.

A diferencia de los cargos del gobernador y del procurador provinciales, los officiales, al menos en las fechas tardías recogidas por el Digesto (12,
1,34), podían estar en servicio de forma estable muchos años seguidos. En realidad, estos cargos militares en la organización provincial formaron ya parte de las reformas de Augusto y Agripa pero no sería hasta ahora, a principios del siglo III, cuando su presencia en el praetorium consulare se revele como mayoritaria.

Los estudios de B. Rankov (1999), J. NelisClement (2000) y recientemente J. J. Palao (2006) nos facilitan en gran forma la comprensión de como estaba estructurada la jerarquía del officium provincial. G. Alföldy (2007) y P. Le Roux (1998) han estudiado de forma específica los militares documentados en la epigrafía tarraconense. Los grados de estos militares puestos por orden de escalafón de mayor a menor serían los siguientes. En primer lugar el princeps officium, o jefe del gabinete que debía ser un centurión con experiencia en el propio officium; le ayudaba el optio praetorii, un segundo centurión al frente de todos los subordinados. Eran éstos dos o tres cornicularii, cuyo nombre hacía referencia a un pequeño cuerno o corniculum, puesto en el casco como enseña al valor. Con el grado de decuriones, sus funciones eran la correspondencia y el reparto de los asuntos a tratar. Tenían como ayudantes a los adiutores officii corniculariorum, con categoría de soldados immunes, exentos de tareas pesadas. Seguían dos o tres commentarienses, de grado inferior a los cornicularii, responsables de los archivos y de los procesos verbales judiciales. Hemos de pensar que en las oficinas del gobernador se debían redactar las sentencias judiciales, llevar al día la correspondencia y recibir los informes sobre la actividad militar en la provincia en todo lo relativo a traslados, ascensos, licencias y nuevos reclutamientos.

Un grupo aparte y de categoría inferior estaba compuesto por los agentes de policía y los mensajeros. Eran estos en primer lugar los speculatores, agentes de información, encargados de las detenciones y los interrogatorios. Seguían los beneficiarii que aseguraban las comunicaciones estratégicas en el interior de la provincia con diferentes stationes repartidas a lo largo de la misma. En tercer lugar los frumentarii eran mensajeros especiales más allá de los límites de la provincia, pero también podían ser espías y ejecutores, disponiendo de permisos y derechos especiales de transporte y alojamiento. Todos estos officiales compartían como insignia la lanza adornada de los beneficiarii. A sus órdenes actuaban una serie 
de soldados immunes: quaestionarii, implicados en la actividad judicial, librarii, notarii, exceptores, tesserarius y exacti, distintos tipos de secretarios, archiveros y copistas.

Una dedicatoria a Minerva por parte del beneficiarius L. Valerius Flavus (RIT 43), miles de la legión VII, pro salute collegio stratorum, atestigua la existencia en Tarraco de una asociación militar de tipo mixto que agruparía a los distintos officiales de la VII legión instalados en Tarraco, bajo su denominación común de "ayudantes" o stratores del gobierno provincial (fig. 10). La lápida ha de datarse con anterioridad al año 197 por no aparecer el titulo de Pia en el título de la legión. Como en el caso de los collegia de las profesiones civiles, la función de estos collegia militaria era facilitar las relaciones corporativas entre sus miembros a partir de la celebración conjunta de festividades y la asistencia a las reuniones en su sede o schola. El pago de una cuota y el cumplimiento de un determinado reglamento eran obligados, teniendo asegurada los asociados su atención funeraria por los compañeros en caso de morir intestados.

Las estimaciones sobre el número de integrantes de este officium es que no pasaría de los 100 miembros. El pedestal ofrendado al praeses Hedius Rufus fue ofrecido como hemos explicado por catorce militares, dos cornicularii, dos commentarienses y diez speculatores, que podemos considerar la plana mayor del officium. En el caso del pedestal ofrendado a Flavius Titianus los militares que acompañaban al princeps officii eran 38 pero desconocemos sus cargos respectivos.

Ciertamente, todos estos officiales destinados en las oficinas provinciales pudieron por su reducido número vivir alojados de forma privada en diferentes casas de la ciudad. En el caso de los beneficiarii T. Cornelius (RIT 190) y Valerius Atticus(RIT 197) sabemos que ambos vivían como huéspedes en casas privadas y fueron enterrados por sus matronas respectivas. La vida en Tarraco de estos militares quedaba marcada por obligaciones y destinos que los alejaban de la sociedad civil, fortaleciendo entre ellos los lazos corporativos y de hermandad que se mantenían después de su licencia y conversión en veterani (Le Roux 1998; Alföldy 2007). Muchos de estos militares tenían con ellos a sus padres, estaban casados o disponían en Tarraco de propiedades y esclavos. Sus lápidas funerarias les fueron dedicadas por sus padres y madres, mujeres, hijos, libertos o esclavos liberados cumpliendo cláusulas testamentarias. Cuando estos militares no estaban casados era normal que sus epitafios corrieran a cargo de sus propios compañeros, bien por haber sido nombrados herederos (RIT 212) o por una razón corporativa o colegial. Ese fue el caso por ejemplo del speculator $Q$. Annius Aper (RIT 205), muerto en Tarraco sin hacer testamento (in\{ in\}testato defuncto), cuyo entierro y ara funeraria fueron asumidos por siete de sus compañeros (collegae eius); también del beneficiarius consularis de origen africano L. Aufidius Felix, enterrado por su paisano (municeps), el speculator Gargilius Rufus, de la legión VII (RIT 187) o de diferentes soldados y veteranos que fueron enterrados en Tarraco a cargo de sus compañeros, commilitoni y contubernali.

Las tumbas de estos soldados, en general con altares funerarios bien trabajados, esculturas y en algunos casos lujosos mausoleos con dinteles epigráficos de un tamaño notable, se encuentran repartidas por las necrópolis situadas en torno a la vía Augusta tanto en dirección noreste hacia Barcino y Roma como en dirección suroeste hacia el vado del Francolí y las vías hacia Dertosa o Ilerda (Alföldy 2007: 516-517). Examinando las

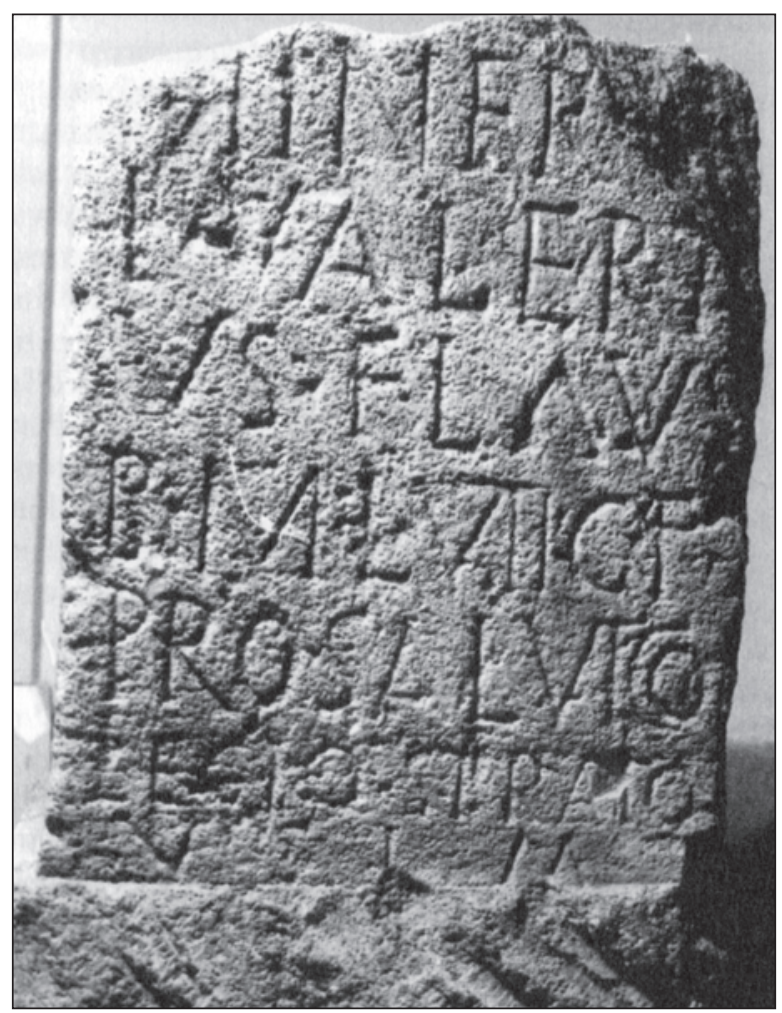

Figura 10. Dedicatoria a Minerva del beneficiarius L. Valerius Flavus "a la salud del colegio de los stratores" ( RIT 43). 
necrópolis en su conjunto no parece que existiera una zona concreta de necrópolis militar aunque $\mathrm{G}$. Alföldy (2007: 510-511) recuerda que las tumbas de los beneficiarii se escalonan principalmente a lo largo de la vía en dirección a Barcino.

Respecto al lugar de residencia del selecto colectivo de los officiales hemos pues de considerar que su lugar de trabajo fue el praetorium consulare, entendido éste como el gran conjunto arquitectónico que denominamos foro provincial de Tarraco. Su lugar de residencia fueron las posadas y albergues urbanos (cauponae y hospitia) o tuvieron sus propias casas alquiladas o compradas en la ciudad.

\section{LOS VETERANOS DE LA LEGIÓN VII Gemina INSTALAdOS EN TARRACO.}

En el momento de su retirada del ejercito, el militar romano recibía la honesta missio y recibía una serie de premios y privilegios (praemia) que incluían una paga extraordinaria (missio numaria) o el derecho a recibir un lote de tierras (missio agraria). Desde entonces el soldado pasaba a ser un veteranus. El tiempo oficial de servicio activo en una legión se situaba en época alto-imperial en 25 años, pero los estudios estadísticos sobre los epígrafes funerarios de los militares de la legión VII sitúan la media del tiempo de servicio (stipendium) en torno a los 15,5 años. Según los trabajos estadísticos de Juan José Palao (2006), la esperanza de vida de los militares de la Legión VII en servicio activo rondaba los cuarenta años de edad, y la de aquellos que habían podido licenciarse como veteranos llegaba a los 64,5 años.

A principios del siglo III d.C. el veterano $Q$. Caelius Felix celebró su honesta missio después de haber sido commentariensis praesidis $\mathrm{pHc}$, responsable del archivo provincial y de la sesiones judiciales orales del gobernador (praeses) provincial. Cumpliendo una promesa realizada a su llegada a Tarraco años atrás como simple speculator, Celio dedicó un altar en el recinto provincial conjuntamente a Júpiter Optimo Maximo, al Genius de la Legión VII Gemina Pia Felix y a la Fortuna Redux, la diosa Fortuna "del buen regreso" ( $A E$ 1999, 967). Resulta evidente que al licenciarse Celio esperaba emprender el regreso a su comunidad de origen pero no fue éste el caso más habitual. Acabados los años de servicio, los militares preferían frecuentar los ambientes a los que ya se habían acostumbrado y la cercanía de sus viejos camaradas de armas. Por ello, una vez recibida la paga, tendían a instalarse de forma mayoritaria en las proximidades de los lugares donde habían prestado los últimos años de servicio.

Esta pudo ser la razón por la cual Tarraco presenta el mayor número de testimonios epigráficos de veteranos de la legión VII de toda Hispania. Siguen la ciudad de Emerita, la otra capital provincial con presencia de soldados en el officium de gobierno, Asturica Augusta, capital de conventus y sede del procurador minero desde donde se gestionaban las principales minas de oro del noroeste peninsular y en cuarto lugar la zona de Tritium Magallum, en la Rioja, un importante centro industrial de producción de cerámicas que atrajo igualmente por la calidad de sus tierras y las buenas comunicaciones a un buen número de veteranos de la legión. Instalados en Tarraco con sus familias, los veteranos podían buscar alguna pequeña propiedad agraria en el entorno de la capital o desempeñar un oficio de acuerdo con la especialidad adquirida en los años de servicio activo.

\section{Un Último apunte. Aproximación al CONTEXTO HISTÓRICO DE LA DEDICATORIA del Centurión Aurelio Décimo.}

Es probable que el centurión Aurelio Décimo coincidiera en Tarraco con el joven senador de origen africano Lucio Septimio Severo, más tarde emperador, que sabemos por sus biógrafos estuvo en la ciudad como ayudante jurídico del gobernador entre los años 178 y 180. Eran años difíciles para todos, cuando el emperador Cómodo, saludado en el epígrafe, iniciaba su mandato en medio de asesinatos y conspiraciones palaciegas, con todo tipo de enfrentamientos fronterizos en el Rhin, el Danubio, Britannia y las dos Pannonias, incluso en la siempre pacífica Bética donde la ciudad de Singilia Barba sabemos fue atacada en el 179 por una incursión de los mauri perseguidos a continuación por el procurador de la Lusitania $C$. Vallius Maximus (Alföldy,1985).

La sociedad romana estaba enfrascada en una profunda crisis. Según la Historia Augusta llegó a haber 25 cónsules en un solo año ya que el cargo senatorial de mayor reputación se había puesto a la venta, ricos libertos fueron admitidos como senadores y el gobierno de las provincias pudo ser ofrecido al mejor postor. Todo ello en una Roma 
castigada por la peste y los grandes incendios mientras las provincias eran sometidas a revueltas internas motivadas por el hambre. La "Guerra de los desertores" (bellum desertorum) se extendía en los límites entre la tarraconense y la narbonense con grupos de bandoleros compuestos por desertores del ejército, campesinos arruinados y aventureros de todo tipo cuyas correrías llegaron a extenderse por toda la Galia en los años 187 y 188 convertidos en un auténtico ejército bajo el mando de Materno finalmente derrotado por el entonces gobernador de Aquitania Pescennius Niger (SHA, Comm, XVI, 2; Niger, III, 3-5).

Eran momentos de tensión en los que sabemos que la legión VII desde su base leonesa tuvo que desplazar vexillationes para mantener el orden. En Emporiae, el centurión Junio Víctor al mando de una de ellas reuniría a sus hombres para dedicar un altar a Júpiter celebrando el cumpleaños del águila (ob natalem Aquilae), es decir el aniversario de la fundación de la legión (IRC 3,14). Más allá de los Pirineos, en la pequeña y sagrada ciudad de Glanum, los ciudadanos tuvieron que volver a tomar las armas para formar una unidad de combate de cerca de 700 hombres al mando del tribuno G. Licinius Macrus. Fueron los milites glanicorum que sub vexsillo fuerunt, los soldados de Glanum partidos bajo sus estandartes, recordados por el optio C. Pompeius Cornutus que levantó un altar a Hércules para su salud y feliz regreso al mando del tribuno Macro y sus centuriones (AE 1954, 102; Le Bohec, 1999).

Hemos pues de preguntarnos en último lugar si el contingente de jinetes entrenado en Tarraco por los centuriones Aurelio Décimo y Aurelio Lucilio tenía como fin convertirse en una guardia de corps tradicional o en realidad se estaba formando una pequeña unidad rápida de caballería a modo de una cohors equitata para atender posibles conflictos en una época especialmente turbulenta. Su tamaño de cualquier forma tuvo que limitarse a una simple centuria si a su frente se puso un centurión y no un prefecto. Fuera como fuese, la historia militar de la Tarraco imperial acabaría unas décadas más tarde de forma muy poco brillante. En el año 260 d.C. Tarraco, la orgullosa capital provincial romana de la Hispania citerior, una ciudad con quinientos años de historia, sede del gobierno, la justicia y la administración provincial fue ocupada en un rápido golpe de mano por tribus germanas sin ninguna experiencia en tácticas de asedio (AURELIO
VICTOR, Libro de los Césares, XXXIII, 3: "Tribus de francos, después de saquear la Galia, poseyeron Hispania, siendo devastada y casi saqueada la ciudad de Tarraco y, habiendo conseguido ocasionalmente barcos, una parte de ellos llegó hasta Africa"). Nunca hasta entonces la ciudad había sido atacada.

\section{BIBLIOGRAFIA:}

ALFÖLDY, G. (1969): Fasti Hispanienses. Senatorische Reichsbeamte und Offiziere in den spanischen Provinzen des Römischen Reiches von Augustus bis Diokletian, Wiesbaden, 18-19.

- (1985): Bellum Mauricum. Chiron, 15, 91-109.

- (1991): Epigraphica Hispanica XII. Eine neue Inschrift aus Tarraco: Dispensator census Sarmatici oder discens armaturae? ZPE, 87, 163167.

- (2007): El ejército romano en Tarraco. En: MORILLO, A. (ed.). El ejército romano en Hispania. Guía Arqueológica. León: Universidad de León, 503-521.

ARCE, J. (1981): Inestabilidad política en Hispania durante el siglo II d.C., Archivo Español de Arqueología, 54 (1981), 101 ss; reed. en ID, España entre el mundo antiguo y el mundo medieval, Madrid (1988).

BARBIERI, G. (1941): Il Praefectus Orae Maritimae. Rivista di Filologia e di istruzione classica, 19, 268-280.

- (1946): Ancora sul praefectus orae maritimae. Rivista di Filologia e di istruzione classica, 74, 166-171.

CONNOLLY, P. (1989): Las legiones romanas. Móstoles: Anaya.

DESBAT, A. (2004): Nouvelles données sur les origines de Lyon et sur les premiers temps de la colonie de Lugdunum. En: RUIZ DE ARBULO; J. (Ed.) Simulacra Romae. Roma y las capitales provnciales del Occidente Europeo. Estudios Arqueologicos, (Tarragona, 2002), Tarragona (2004), 201-222.

Diz Epi: DE RUGIERO, E. (1906). Dizionario Epigrafico di Antichità Romane. Roma: L'Erma di Bretschneider (ristampa 1962).

DOMASZEWSKI, A. von (1895): Die Religion des römischen Heeres. Reed. Whitefisch,USA: Kessinger Publishing (2009).

- (1908): Die Rangordnung des römischen Heeres. Bonn: A. Marcus und E. Weber. 
HAENSCH, R. (1997): Capita prouinciarum. Statthaltersitze und Provinzialverwaltung in der römischen Kaiserzeit. Mainz:Philipp von Zabern.

- (2004): Les capitales des provinces germaniques et de la Rhetie: des vieilles questions et de nouvelles perspectives. En: RUIZ DE ARBULO, J. (Ed.) Simulacra Romae. Roma y las capitales provinciales del Occidente Europeo. Estudios Arqueológicos (Tarragona, 2002), Tarragona 2004, 307-325.

JARRET, M.G. (1976): Maryport, Cumbria: A Roman fort and its Garrison, Kendal.

LE BOHEC, Y. (2008): El ejército romano. Barcelona: Ed. Ariel.

LE ROUX, P. (1982): L'armée romaine et l'organisation des provinces ibériques d'Auguste à l'invasion de 409 (Publications du Centre Pierre Paris 8). Paris.

- (1998): Ejército y sociedad en la Tarraco romana, Butlleti Arqueologic, 19-20, 83-107.

MACIAS, J.M. y FIZ, I. Dirs. (2007): Planimetria Arqueològica de Tàrraco, Tarragona: ICAC.

NELIS-CLEMENT, J. (2000): Les beneficiarii: militaires et administrateurs au service de l'Empire. Paris: de Boccard.

PALAO, J.J. (2006): Legio VII Gemina (Pia) Felix. Estudio de una legión romana. Salamanca: Ediciones de la Universidad de salamanca.

PEREA, S. ( 1998): Los Stratores en el ejército romano imperial : (funciones y rangos). Madrid: Ed. Signifer.

RIT: AlFÖLDY, G. (1975). Die römischen Inschriften von Tarraco. Berlín: Walter de Gruyter.
RANKOV, B. 1999: The governor's men: the officium consularis in provincial administration. En: GOLDSWORTHY,A. HAYNES, I. (Eds). The Roman Army as a commmunity. JRA Suppl. 34. Portsmouth, Rhode Island, 15-34.

ROLDAN, J.M. (1974): Hispania y el ejército romano. Salamanca.

RUIZ DE ARBULO, J. (1994): Edificios públicos, poder imperial y evolución de las élites urbanas en Tarraco (s. II-IV d. C.), Ciudad y comunidad cívica en Hispania (s. II-III d. C.), (Madrid, 1990), Madrid, 93-113.

- (1998a): Tarraco. Escenografía del poder, administración y justicia en una capital provincial romana (s. II aC- II dC), Empúries, 51, 31-61.

- (2008): Bauliche Inszenierung und literarische Stilisierung: das Provinzialforum von Tarraco, PANZRAM, S. (Hg.), Städte im Wandel(Hamburg 2005), LIT, Munster, 149-212. Trad. Castellana: Nuevas cuestiones en torno al foro provincial de Tarraco, Butlleti Arqueologic, Ep. V., 29, Tarragona, 2008, 4-66.

SOUTHERN, P. (2007): The roman army: a social and institutional history. Oxford: Oxford Univ. Press.

SPEIDEL, M.A. (1965): Die Equites singulares Augusti. Begleittruppe der römischen Kaiser des zweiten und dritten Jahrunderts. Bonn.

- (1978): Guards of the Roman Armies: an essay on the singulares of the Provinces. Bonn.

- (1994): Riding for Caesar. The Roman Emperor's Horse Guard. Cambridge, Mass: Harvard Univ. Press. 
